\title{
Expression of Very Late Antigen-4 and Lymphocyte Function-Associated Antigen-1 on Peripheral Blood Lymphocytes from Patients with Graves Disease
}

\author{
ARTUR BOSSOWSKI, MIROSŁAWA URBAN, ANNA STASIAK-BARMUTA, AND \\ DARIUSZ TUROWSKI
}

\begin{abstract}
Second Department of Children's Diseases [A.B., M.U.], Department of Pediatric Allergology [A.S.-B.], Department of Pediatric Laboratory Diagnostics [D.T.], Medical Academy of Biatystok, Biatystok, Poland
\end{abstract}

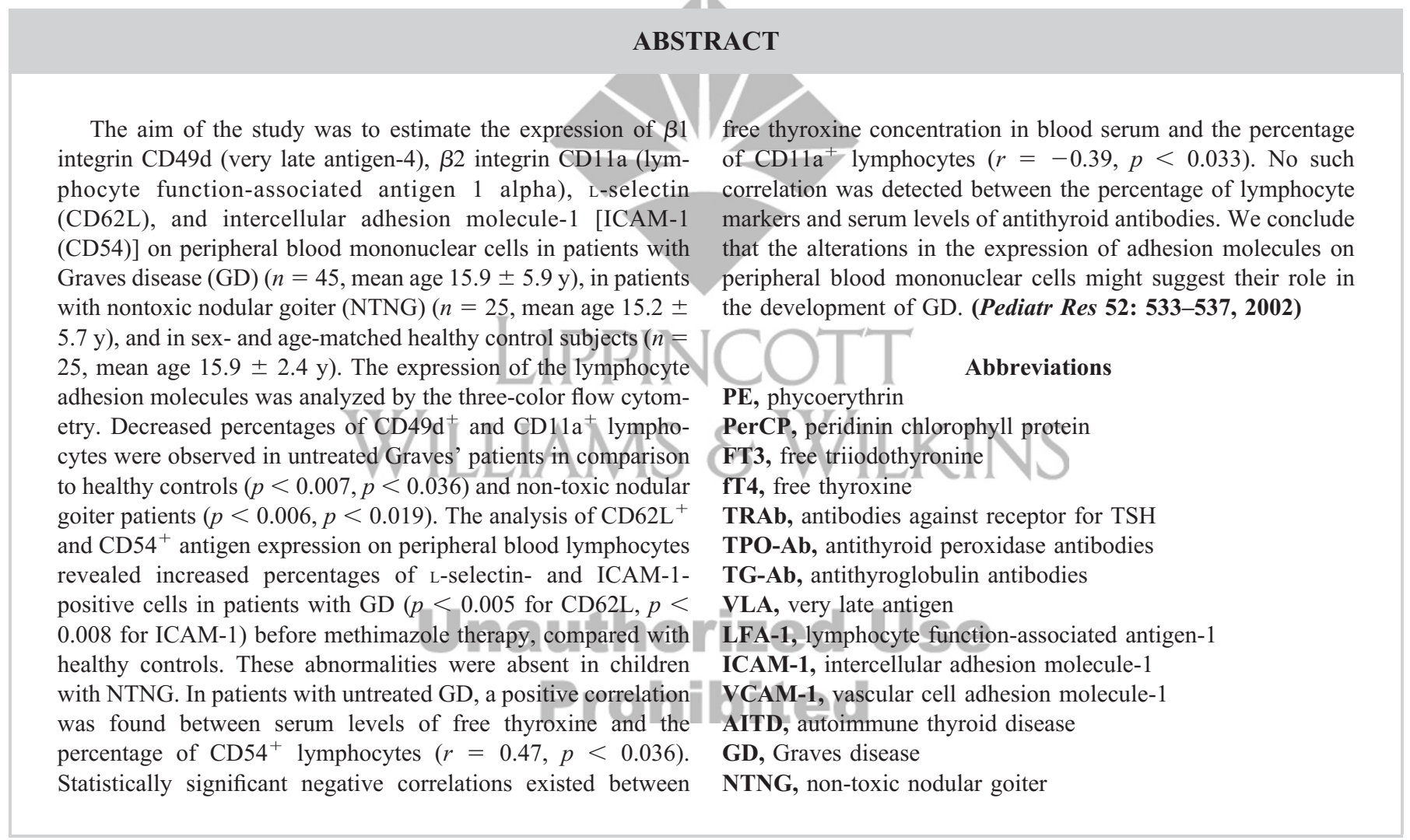

GD is an AITD characterized by lymphocytic infiltration of the thyroid gland and the production of TRAb, symporter $\mathrm{Na}^{+} / \mathrm{I}^{-}$, thyroglobulin, and thyroperoxidase antigen (1-3). In addition, literature data underline the role of cytokines and

Received October 12, 2001; accepted April 9, 2002.

Correspondence: Artur Bossowski, M.D., Second Department of Children's Diseases, Medical Academy of Białystok, 15-274 Białystok, ul. J. Waszyngtona 17, Poland; e-mail: abossowski@hotmail.com

A preliminary version of this study was presented at 11th International Congress of Immunology 2001, Stockholm, Sweden, and at the 6th Pediatric Endocrinology Meeting LWPES/ESPE 2001, Montreal, Canada.

DOI: 10.1203/01.PDR.0000030880.20888.3D adhesion molecules as new unspecific markers of the autoimmune process in GD (4-7).

Adhesion molecules are the cellular membrane proteins expressed on activated lymphocytes, found to play a pivotal role in the initiation, localization, and perpetuation of thyroid autoimmune disease. They belong to three structurally related families: integrin, Ig supergene, and selectin. Integrins constitute a family of widespread $\alpha$ - $\beta$ heterodimeric adhesion receptors that mediate cell attachment to extracellular matrix proteins (fibronectin, laminin, collagen) and cell-cell interactions, which have been grouped in four distinct subfamilies based on $\beta$-subunit utilization (8). Members of the $\beta 1$ subfamily called VLA contain a common $\beta 1$ chain (CD29), noncovalently 
associated with at least one of nine different $\alpha$ chains. A particular role in this group has been assigned to VLA- $\alpha 4$, constitutively expressed by most leukocytes, which mediates cell interaction with fibronectin and with counter-receptor from the Ig supergene family VCAM-1 (CD106) on cytokineactivated endothelial cells $(9,10)$. The $\beta 2$ integrin subfamily consists of either CD11a, CD11b, or CD11c chains with the $\beta 2$ subunit (CD18) (11). An important pathway for lymphocyte adhesion is the LFA-1 (CD18/CD11a) present on lymphocytes $\mathrm{B}$ and $\mathrm{T}$ and granulocytes, which interact with three counterreceptors from the Ig supergene family-ICAM-1, -2, and -3 (12-14). The ICAM-1 (CD54) molecule is expressed on thyrocytes, activated epithelial cells, endothelial cells, and leukocytes. ICAM-2 is constitutively localized in endothelial cells, whereas ICAM-3 is only present on cells from the leukocyte lineage $(15,16)$.

These two molecular complexes, VLA-4/VCAM-1 and LFA-1/ICAM-1, -2, -3, regulate adhesion and migration of lymphocytes and monocytes through the vascular walls, similarly to L-selectin (CD62L), which is expressed mainly on lymphocytes and neutrophils and plays the main role in homing of $\mathrm{T}$ cells into lymphoid organs and to the area of the local inflammation $(13,17)$.

Several studies have been concerned with the expression of these molecules on peripheral blood mononuclear cells at the onset of GD in humans $(18,19)$. Results from one study suggest that patients with hyperthyroidism display decreased expression of integrins (18). Recently, another study has shown that in patients with newly diagnosed GD, the expression of ICAM-1 (CD54) is higher than in controls (19).

In the present study, we determined the expression of $\beta 1$ integrin CD49d (VLA-4 $\alpha$ ), $\beta 2$ integrin CD11a (LFA-1 $\alpha$ ), L-selectin (CD62L), and ICAM-1 (CD54) on peripheral blood mononuclear cells in patients with newly diagnosed GD before and after 2-6 mo and 18-24 mo of methimazole therapy, in levothyroxine-suppressed patients with nontoxic nodular goiter (NTNG), and in healthy controls, to elucidate the relationship with circulating antithyroid antibodies and a possible role of adhesion molecules as markers of inflammatory activity.

\section{PATIENTS AND METHODS}

We studied a group of 70 patients (10 boys and 60 girls) aged $8-19$ y (mean age $15.5 \pm 5.8 \mathrm{y})$ with GD $(n=18$ before and $n=27$ after methimazole therapy, mean age $15.9 \pm 5.9 \mathrm{y}$ ) and NTNG $(n=25$, mean age $15.2 \pm 5.7 \mathrm{y})$, and a group of 25 sex- and age-matched healthy control subjects with no personal or family history of thyroid and autoimmune disease ( 2 boys and 23 girls, mean age $15.9 \pm 2.4$ y). Healthy controls were euthyroid, with negative antithyroid antibodies. None of the subjects had experienced acute infection or other diseases during the period of $8 \mathrm{wk}$ before sample collection. The diagnosis was based on clinical examination, laboratory tests, and ultrasonography of the thyroid gland. In patients with nodular goiter, fine-needle biopsy was also performed (in all the cases the changes were mild).

The untreated patients with GD had low levels of TSH (mean: $0.21 \pm 0.72 \mathrm{uIU} / \mathrm{mL}$ ), high thyroid hormone levels
(fT3, mean: $12.7 \pm 11 \mathrm{ng} / \mathrm{L}$; fT4, mean: $3.09 \pm 1.5 \mathrm{ng} / \mathrm{dL}$ ), and elevated levels of antithyroid antibodies (TRAb, mean: $19.47 \pm 9 \mathrm{U} / \mathrm{L}$; TPO-Ab, mean: $1897 \pm 1570 \mathrm{IU} / \mathrm{mL}$; and TG-Ab, mean: $1956 \pm 1608 \mathrm{IU} / \mathrm{mL}$ ). Patients with two or three positive antithyroid antibodies were selected for the study.

Eighteen patients with NTNG were clinically and biochemically euthyroid, with the following mean hormone levels: fT3 $3.24 \pm 0.25 \mathrm{ng} / \mathrm{L}$, fT4 $1.17 \pm 0.25 \mathrm{ng} / \mathrm{dL}$, hTSH $1.43 \pm 0.46$ $\mathrm{uIU} / \mathrm{mL}$, and with normal concentration of antithyroid antibodies: TPO-Ab $60 \pm 22 \mathrm{IU} / \mathrm{mL}, \mathrm{TG}-\mathrm{Ab} 83 \pm 51 \mathrm{IU} / \mathrm{mL}, \mathrm{TRAb}$ $1.46 \pm 1.3 \mathrm{U} / \mathrm{L}$. All the patients met the following criteria: 1 ) absence of clinical evidence of disease other than thyroid autoimmune disease, 2) no history of systemic diseases, 3) no application of immunoactive drugs, and 4) normal liver and kidney function.

Schedule of study. Analysis of lymphocyte markers was performed at the first visit. Then, patients with GD were treated with methimazole, at an initial dose of $1 \mathrm{mg} / \mathrm{kg} / \mathrm{d}$ (max. 30 $\left.\mathrm{mg} / \mathrm{m}^{2} / \mathrm{d}\right)$ in combination with propranolol $(0.5-1 \mathrm{mg} / \mathrm{kg} / \mathrm{d})$. Once clinical euthyreosis had been obtained (second evaluation of lymphocytes, between 2 and 6 mo), methimazole doses were reduced by $5-10 \mathrm{mg}$ to reach the maintenance dose of 5-10 mg. Levothyroxine was added if hypothyroidism appeared. Patients were followed-up for 36 mo after the diagnosis. Twenty eight GD patients achieved control of hyperthyroidism by receiving methimazole for 18-24 mo and remained euthyroid after the suppression of therapy (third period of lymphocyte reevaluation). We used 131-iodine therapy in six cases resistant to thyrostatic treatment with relapse of hyperthyroidism and surgery in one case (all the cases were reevaluated 3 mo after the therapy).

Patients with NTNG received suppressive doses of thyroxine (mean $75 \pm 25 \mu \mathrm{g} / \mathrm{d}$ ) for the period of 6-18 mo (mean $13 \mathrm{mo}$ ).

Blood samples were collected between 0730 and $0900 \mathrm{~h}$ for the measurement of serum fT3, fT4, hTSH, and antithyroid antibodies, and (in an EDTA tube) for morphologic parameters and cluster designation (CD) phenotyping. All parents of patients and controls gave informed consent before enrollment. The protocol for the study was approved by the Local Ethical Committee at $\mathrm{Bia} \geq$ ystok Medical Academy.

Immunologic marker analysis. The peripheral blood samples were analyzed following previously described techniques (20).

Three-color immunophenotyping of lymphocytes was performed by a lysed whole-blood method using combinations of mouse MAb directly conjugated to Simultest (BD Biosciences, Franklin Lakes, NJ, U.S.A.). All samples were processed using the Q-Prep whole blood lysis system (Beckman Coulter, Inc., Fullerton, CA, U.S.A.). Briefly, $100-\mu \mathrm{L}$ samples of whole blood were stained with $10 \mu \mathrm{L}$ of the following three-color MAb (Simultest, Becton Dickinson Immunocytometry System, San Jose, CA, USA) directly conjugated to FITC, PE, or PerCP: CD3-PerCP(Leu-4)/CD54-PE, CD3-PerCP(Leu-4)/ CD49d-PE，CD3-PerCP(Leu-4)/CD62L-FITC，CD3-PerC$\mathrm{P}(\mathrm{Leu}-4) / \mathrm{CD} 11 \mathrm{a}-\mathrm{FITC}$. After incubation at room temperature for $20 \mathrm{~min}$, the samples were than processed with a 35-s cycle on a rapid no-wash whole blood lysis work station. A minimum of $10^{4}$ cells were analyzed by Coulter EPICS XL flow 
cytometer. The percentage of positive cells was determined by setting the lower limit over the nonspecific fluorescence with a suitable control.

Thyroid hormones and autoantibodies. Serum levels of anti-TRAb were routinely determined by a radio receptor assay (TRAK-Assay, Brahms Diagnostica GmbH, Berlin, Germany). The test is based on the binding of the TSH receptor with Ig present in blood serum and directed against this receptor, and with radioiodine-labeled TSH $\left({ }^{125} \mathrm{I}-\mathrm{TSH}\right)$. TRAb values $<9$ $\mathrm{U} / \mathrm{L}$ were considered TRAb negative; TRAb concentrations above $14 \mathrm{U} / \mathrm{L}$ were positive. The range between 9 and $14 \mathrm{U} / \mathrm{L}$ was defined as borderline (gray zone). The sensitivity of the TRAK-Assay was $<2.4 \mathrm{U} / \mathrm{I}$. Intra- and interassay coefficients of variation were $5.1 \%$ and $10.2 \%$, respectively.

$\mathrm{TPO}-\mathrm{Ab}$ and TG-Ab were determined in the sera using the immunodiagnostic test Varelisa (variable enzyme-linked immnosorbent assay, Pharmacia Upjohn Diagnostics GmbH, Freiburg, Germany). These tests use human microsomal antigen for anti-TPO assay and human thyroglobulin as an antigen for anti-TG determination. Results were read on a photometer (STAT FAX 303 PLUS, ANALCO-GBG) at $450 \mathrm{~nm}$ wavelength, with absorption values proportional to the level of anti-TPO or anti-TG antibodies. Normal range for TG-Ab was $<500 \mathrm{IU} / \mathrm{mL}$ and for TPO-Ab was $<50 \mathrm{IU} / \mathrm{mL}$. The levels of fT4, fT3, and hTSH in blood serum were determined on a mini-analyzer (Bio Mérieux, Charbonnières les Bains, France), based on test Varelisa (Pharmacia Upjohn Diagnostics GmbH \& Co.KG. Freiburg, Germany), combining the immunoenzymatic method with the final fluorescence measurement (ELFA). Normal range of fT4 was $0.71-1.55 \mathrm{ng} / \mathrm{dL}$, fT3 was $2.6-5.4 \mathrm{ng} / \mathrm{L}$, and hTSH was $0.32-5,0 \mu \mathrm{IU} / \mathrm{mL}$.

Statistical analysis. The results were expressed as the means $\pm \mathrm{SD}$. Comparison of the percentages of lymphocytes expressing adhesion molecules between the groups was carried out using $t$ test, confirmed by Mann-Whitney $U$ test. T value was considered statistically significant at $p<0.05$. For correlation analysis, Pearson's and Spearman's tests were used. Mathematical and statistical calculations were permformed with Statistica 5.0 (StatSoft, Tulsa, OK, U.S.A.).

\section{RESULTS}

Patients with GD showed a decreased percentage of both $\mathrm{CD}_{4} 9 \mathrm{~d}^{+}$and $\mathrm{CD} 11 \mathrm{a}^{+}$lymphocytes, compared with NTNG patients and healthy controls. After 2-6 mo of methimazole treatment, the percentage of $\mathrm{CD} 11 \mathrm{a}^{+}$lymphocytes normalized, whereas the percentage of $\mathrm{CD} 49 \mathrm{~d}^{+}$cells was still significantly lower than in healthy children. However, after 18-24 mo of therapy when GD patients were in long-term clinical and biochemical remission, the percentages of both $C D 49 \mathrm{~d}^{+}$and $\mathrm{CD}_{11 \mathrm{a}^{+}}$lymphocytes normalized. There was no significant difference between the proportions of these lymphocyte markers in patients with NTNG and healthy controls (Fig. 1).

The analysis of $\mathrm{CD}_{2} \mathrm{~L}^{+}$and $\mathrm{CD} 54^{+}$antigen expression on peripheral blood mononuclear cells revealed increased percentages of L-selectin- and ICAM-1-positive cells in patients with hyperthyroidism before thyrostatic treatment, compared with healthy controls and euthyroid patients with GD. After 2-6 mo

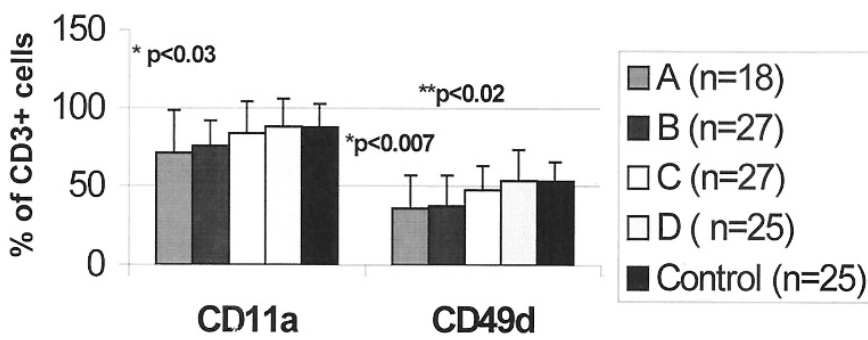

Figure 1. Expression of LFA-1a and VLA-4a on peripheral blood lymphocytes in patients and in control group. Patients with GD: Group A-before treatment (untreated hyperthyroidism); Group B-after 2-6 mo of methimazole treatment; Group C-after 18-24 mo of therapy. Group D-patients with nontoxic nodular goiter. Group $\mathrm{K}-$ healthy children. Values are means $\pm \mathrm{SD}$; *Group A $v s$ controls; **Group B $v s$ controls.

of methimazole treatment, the percentages of $\mathrm{CD} 62 \mathrm{~L}^{+}$and $\mathrm{CD} 4^{+}$cells dropped, but only the percentage of $\mathrm{CD} 54^{+}$ monocytes was still significantly higher than in healthy children. However, after 18-24 mo of therapy, the percentage of $\mathrm{CD} 62 \mathrm{~L}^{+}$lymphocytes returned to normal. These abnormalities were absent in children with NTNG (Fig. 2, Table 1).

We studied the correlation between the concentration of thyroxine and percentages of lymphocytes expressing adhesion molecules. In patients with untreated GD, a positive correlation was found between serum levels of fT4 and the percentage of $\mathrm{CD} 4^{+}$lymphocytes $(r=0.47, p<0.036)$. Statistically significant negative correlations existed between fT4 concentration in blood serum and the percentage of $\mathrm{CD} 11 \mathrm{a}^{+}$lymphocytes $(r=-0.39, p<0.033)$. No such correlation was detected between the percentages of lymphocyte markers and serum levels of antithyroid antibodies.

After 131 -iodine therapy (in six cases), GD patients were reevaluated ${ }^{-}$for the percentages of $\mathrm{CD}^{-} 9 \mathrm{~d}^{+}, \mathrm{CD} 11 \mathrm{a}^{+}$, $\mathrm{CD}_{2} \mathrm{~L}^{+}$, or $\mathrm{CD} 54^{+}$lymphocytes. No significant changes were noted in the proportions of cells expressing these antigens when compared with the percentages obtained at the diagnosis.

\section{zeo usediscussion}

The increased expression of adhesion molecules on endothelium and lymphocytes is caused by the activation of locally produced cytokines (tumor necrosis factor- $\alpha$, interferon- $\gamma$, IL-1) which are released during the inflammatory process (10).

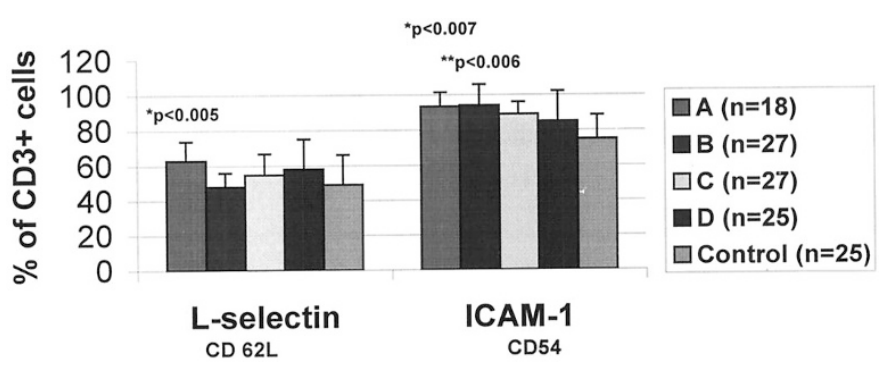

Figure 2. Expression of $\mathrm{CD} 62 \mathrm{~L}^{+}$and $\mathrm{CD} 54^{+}$mononuclear cells on peripheral blood in patients and in the control group. Patients with GD: Group A - before treatment (untreated hyperthyroidism); Group B - after 2-6 mo of methimazole treatment; Group C-after 18-24 mo of therapy. Group D-patients with nontoxic nodular goiter. Group $\mathrm{K}$ - healthy children. Values are means $\pm \mathrm{SD} ; *$ Group A $v s$ controls; **Group B $v s$ controls. 
Table 1. Percentages of positive peripheral blood lymphocytes in healthy controls and in patients with Graves' disease (before therapy) and nontoxic nodular goiter

\begin{tabular}{|c|c|c|c|}
\hline & $\begin{array}{l}\text { Graves' disease } \\
\quad(n=18)\end{array}$ & $\begin{array}{l}\text { Nontoxic nodular goiter } \\
\qquad(n=25)\end{array}$ & $\begin{array}{l}\text { Healthy controls } \\
\quad(n=25)\end{array}$ \\
\hline $\mathrm{CD}^{+}{ }^{+} \mathrm{CD} 11 \mathrm{a}^{+}$ & $71.31 \pm 27^{*}$ & $87.9 \pm 18^{* *}$ & $87.5 \pm 14.8$ \\
\hline $\mathrm{CD}^{+}{ }^{+} \mathrm{CD} 49 \mathrm{~d}^{+}$ & $35.8 \pm 21^{*}$ & $53.37 \pm 20^{* *}$ & $52.9 \pm 12.7$ \\
\hline $\mathrm{CD}^{+} \mathrm{CD}^{+} 4^{+}$ & $93.2 \pm 8.2 *$ & $85 \pm 19^{* *}$ & $75.9 \pm 13.5$ \\
\hline
\end{tabular}

Values are means \pm SD and in percentages for lymphocyte subsets. ${ }^{*} p<0.03$, indicating significant differences between Graves' disease and healthy controls, ** $p>0.05$, no statistically significant differences between nontoxic nodular goiter and controls.

Such induction promotes migration of cells through endothelium during inflammation and contributes to the phasic inflow of various populations of leukocytes. The expression of adhesion molecules on immunocompetent cells is essential for the initiation, localization, and perpetuation of AITD.

In the present study, we found a decreased percentage of lymphocytes expressing CD11a and CD49d molecules in young untreated GD patients. Similar results were obtained by Guerin et al. (18) in adults with hyperthyroidism in comparison to healthy controls, which may suggest that this abnormality is associated with the development of an autoimmune process. Futhermore, these authors underlined the potential role of serum autoantibodies directed against LFA-1 and lymphokines for down-regulation of these glycoproteins and revealed that the defect in membranous LFA-1 synthesis was due to the incorporation of a viral genome in the lymphocytes in GD patients. Hovewer, increased percentages of LFA- $1 \alpha$ - and VLA- $4 \alpha$-positive T cells were observed in the thyroid gland and retroocular tissues in newly diagnosed patients with GD compared with peripheral blood $\mathrm{T}$ lymphocytes from the same patients $(21,22)$. The results of our study imply that the decreased integrin expression in peripheral blood lymphocytes could probably be associated with the increased migration of $\mathrm{CD} 11 \mathrm{a}^{+}$and $\mathrm{CD} 49 \mathrm{~d}^{+}$cells to the thyroid gland. In addition, we found a significant correlation between the level of thyroxine and the percentage of LFA-1 positive cells in children with fresh hyperthyroidism. This could indicate that abnormal thyroid status may lead to systemic immune alterations. Moreover, the present investigation of integrin expression in GD would also seem to be in agreement with our previous findings concerning the increased levels of soluble ICAM-1 and VCAM-1 (extravasation of lymphocytes to the local inflammatory sides is associated with proteolytic cleavage of CD54 antigen from lymphocytes and CD106 antigen from endothelium) in young, untreated patients with GD, inasmuch as ICAM-1 has been found to be a ligand for the LFA-1 and VCAM-1 for the VLA-4 $(13,23)$. In addition, Marazuela et al. (13) suggested that induction of ICAM-1 and VCAM-1 expression in thyroid gland endothelial cells mediated by cytokines might have an important role in localizing and perpetuating the autoimmune response in AITD. We believe that their studies confirm the role of LFA-1/ICAM-1 and VLA-4/ VCAM-1 interactions in the pathogenesis of GD. Moreover, Arao et al. (24) demonstrated that the infiltrating LFA- $1 \alpha$ positive lymphocytes in the thyroid stimulated the proliferation of thyrocytes by lymphocyte-thyrocyte cellular adhesion via the LFA-1/ICAM-1 pathway, which might lead to the devel- opment of a goiter. On the other hand, in the experimental animal model of AITD, this process could be blocked by the addition of ICAM-1 and/or LFA-1 MAb (25). In the future, application of these antibodies may become a new model of therapy in human AITD.

We also found an increased percentage of $\mathrm{CD} 54^{+}$expressing monocytes in children with newly diagnosed GD in comparison to healthy controls and NTNG patients. Similar data were obtained by Lee et al. (19) in untreated adults with hyperthyroidism. They observed enhanced expression of ICAM-1 not only in serum but in the thyroid gland and retroocular tissues due to their activation by antithyroperoxidase antibodies. This, hovewer, was not found in children with GD, who showed only positive correlation between the percentage of CD54 ${ }^{+}$cells and concentration of fT4. We suggest that abnormal expression of CD54 molecules on monocytes is present not only in the affected organs, but also reflects systemic immune alterations due to abnormal concentrations of thyroid hormones.

The present study demonstrated an increased percentage of lymphocytes expressing $\mathrm{L}$-selectin in children with untreated GD in comparison to healthy controls and NTNG patients, thus resembling our previous investigations, which detected high levels of soluble form of L-selectin in the serum of young patients with recent onset of thyroid autoimmunity (26). Hara et al. (27) also observed enhanced activity of L-selectin in adults with hyperthyroidism, suggesting that the action of thyroid hormones and the autoimmune process may contribute to the elevation of its level. The soluble form of L-selectin is shed by proteolytic cleavage from the surface of lymphocytes and neutrophils after activation by antigens during inflammation. It has been proved that loss of surface L-selectin might be necessary to allow leukocytes to migrate into the inflammatory sides (28). This data confirm that L-selectin could be a marker of activity of the autoimmune process in children and adolescents with GD. On the other hand, the elevated level of $\mathrm{CD}_{2} \mathrm{~L}^{+}$cells is associated with growing dominance of Th2 lymphocyte subsets in the peripheral blood in GD patients. Recently, it has been explained that memory T cells expressing L-selectin antigen produce Th2-like cytokines-IL-4, IL-5, and IL-10 — and are more frequent in patients with GD (29-31).

In the present study, methimazole therapy led to clinicalbiochemical remission after $8-12 \mathrm{wk}$ of treatment. The levels of antithyroid antibodies and the percentage of $\mathrm{CD} 11 \mathrm{a}^{+}$and $\mathrm{CD}_{2} \mathrm{~L}^{+}$lymphocytes were normalized after 2-6 mo of treatment, whereas the percentage of $\mathrm{CD}_{5} 4^{+}$and $\mathrm{CD} 49 \mathrm{~d}^{+}$cells returned to normal after 18-24 mo of methimazole therapy. 
The above data indicate strong autoimmune stimulation of the thyroid gland in children and adolescents with GD.

We conclude that the alterations in the expression of adhesion molecules on peripheral blood mononuclear cells might suggest their role in the development of GD as mediators of lymphocyte inflow and adhesion to the tissue of the thyroid gland.

\section{REFERENCES}

1. Ajjan RA, Kemp EH, Waterman EA, Watson PF, Endo T, Onaya T, Weetman AP 2000 Detection of binding and blocking autoantibodies to the human sodium-iodine symporter in patients with autoimmune thyroid disease. J Clin Endocrinol Metab $85: 2020-2027$

2. Akamizu T, Moriyama K, Miura M, Saijo M, Matsuda F, Nakao K 1999 Characterization of recombinant monoclonal antithyrotropin receptor antibodies (TSHRAbs) derived from lymphocytes of patients with Graves' disease: epitope and binding study of two stimulatory TSHRAbs. Endocrinology 140:1594-1601

3. Marazuela M 1999 Lymphocyte traffic and homing in autoimmune thyroid disorders. Eur J Endocrinol 140:287-290

4. Wenisch C, Myskiw D, Gessl A, Graninger W 1995 Circulating selectin, intercellular adhesion molecule-1 and vascular cell adhesion molecule-1 in hyperthyroidism. J Clin Endocrinol Metab 80:2122-2126

5. Bossowski A, Urban M 2001 Serum levels of cytokines in children and adolescents with Graves' disease and non-toxic nodular goiter. J Pediatr Endocrinol Metab 14:741-747

6. Ajjan RA, Watson PF, Weetman AP 1997 Detection of IL-12, IL-13 and IL-15 messenger ribonucleic acid in the thyroid of patients with autoimmune thyroid disease. J Clin Endocrinol Metab 82:666-669

7. Siddiqi A, Monson JP, Wood DF, Besser GM, Burrin M 1999 Serum cytokines in thyrotoxicosis. J Clin Endocrinol Metab 84:435-439

8. Hynes RO 1987 Integrins: a family of cell surface receptors. Cell 48:549-563

9. Larson RS, Springer TA 1990 Structure and function of leucocyte integrins. Immunol Rev 114:181-217

10. Meerchaert J, Furie MB 1995 The adhesion molecules used by monocytes for migration across endothelium include CD11a/CD18, CD11b/CD18 and VLA-4 on monocytes and ICAM-1, VCAM-1 and other ligands on endothelium. J Immunol 154:4099-4112

11. Albelda SM, Buck CA 1990 Integrins and other cell adhesion molecules. FASEB 4:2868-2880

12. Woska IR Ir, Morelock MM, Jeanfavre DD, Bormann BJ 1996 Characterization of molecular interaction between intercellular adhesion molecule-1 and leucocyte function associated antigen-1. J Immunol 156:4680-4685

13. Marazuela M, Postigo A, Acevedo A, Diaz-Gonzalez F, Sanchez-Madried F, de Landazuri MO 1994 Adhesion molecules from the LFA-1/ICAM-1,3 and VLA-4 VCAM-1 pathways on T lymphocytes and vascular endothelium in Graves' and Hashimoto's thyroid glands. Eur J Immunol 24:2483-2490

14. Woska J, Morelock M, Jeanfavre D, Caviness G, Bormann B, Rothlein R 1998 Molecular comparison of soluble intercellular adhesion molecule (sICAM-1) and
sICAM-3 binding to lymphocyte function-associated antigen-1. J Biol Chem 273:4725-4733

15. Tolosa E, Roura C, Marti M, Belfiore A, Pjol-Borrell R 1992 Induction of intercellular adhesion molecule-1 but not of lymphocyte function-associated antigen-3 in thyroid follicular cells. J Autoimmun 5:119-135

16. Van der Stolpe A, Van der Saag PT 1996 Intercellular adhesion molecule-1. J Mol Med 74:13-33

17. Springer TA, Lasky LA 1991 Cell adhesion. Sticky sugars for selectins. Nature 349:196-197

18. Guerin V, Bene MC, Amiel C, Hartemann P, Leclere J, Faure G 1989 Decreased lymphocyte function-associated antigen-1 molecule expression on peripheral blood lymphocytes from patients with Graves' disease. J Clin Endocrinol Metab 69:648653

19. Lee JH, An MA, Jeon JS, Song CU, Shong M, Kim YK, Ro HK 1995 Circulating intercellular adhesion molecule-1 (ICAM-1) in sera of patients with Graves' disease and Hashimoto disease. Korean J Intern Med 10:10-15

20. Laso FJ, Madruga JI, Giron JA, Lopez A, Ciudad J, San Miguel JF 1997 Decreased natural killer cytotoxic activity in chronic alcoholism is associated with alcohol liver disease but not active ethanol consumption. Hepatology 25:1096-1100

21. Nagataki S, Eguchi K 1992 Cytokines and immune regulation in thyroid autoimmunity. Autoimmunity 13:27-34

22. Heufelder AE, Scriba PC 1996 Characterisation of adhesion receptors on cultured microvascular endothelial cells derived from the retroorbital connective tissue of patients with Graves' ophtalmopathy. Eur J Endocrinol 134:51-60

23. Bossowski A, Urban M, Gardziejczyk M, Kitszel A, Rogowski F, Sobotko J 2000 Serum levels of adhesion molecules in children and adolescents with immune and non-immune thyroid diseases. J Pediatr Endocrinol Metab 13:1067-1072

24. Arao T, Morimoto I, Kakinuma A, Ishida O, Zeki K, Tanaka Y, Ishikawa N, Ito K, Ito K, Eto S 2000 Thyrocyte proliferation by cellular adhesion to infiltrating lymphocytes through the intercellular adhesion molecule-1/lymphocyte functionassociated antigen-1 pathway in Graves' disease. J Clin Endocrinol Metab 85:382389

25. Sheeynius A, Camp RL, Pure E 1993 Reduced contact sensitivity reactions in mice treated with monoclonal antibodies to leukocyte function-associated molecule-1 and intercellular adhesion molecule-1. J Immunol 150:655-663

26. Urban M, Bossowski A, Głowińska B 2001 Serum levels of sP-selectin and sLselectin in children and adolescents with Graves' disease. Proceedings of the 14th European Immunology Meeting, EFIS 2000, Poznan, Poland, September 23-27. Monduzzi Editore-Medimond Inc., Bologna, Italy, pp 41-47

27. Hara H, Sugita E, Sato R, Ban Y 1996 Plasma selectin levels in patients with Graves' disease. Endocr J 43:709-713

28. Ley K, Tedder TF 1995 Leukocyte interaction with vascular endothelium. J Immunol 155:525-528

29. Kanegane H, Kasahara Y, Niida Y 1996 Expression of L-selectin (CD62L) discriminates Th1- and Th2-like cytokine-producing memory CD4+ T cells. Immunology $87: 186-190$

30. Itoh M, Uchimura K, Makino M, Kobayashi T, Hayashi R, Nagata M, Kakizawa H, Fujiwara K, Nagasaki A 2000 Production of IL-10 and IL-12 in CD40 and interleukin 4-activated mononuclear cells from patients with Graves' disease. Cytokine 12:688 693

31. Guo J, Rapoport B, McLachlan S 1998 Balance of Th1/Th2 cytokines in thyroid autoantibody synthesis in vitro. Autoimmunity 30:1-9

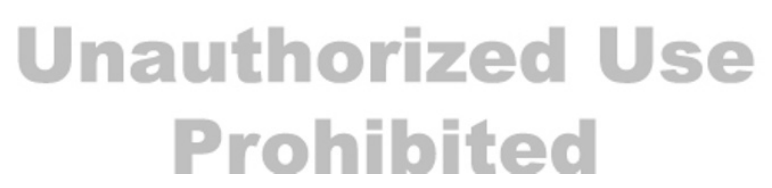

